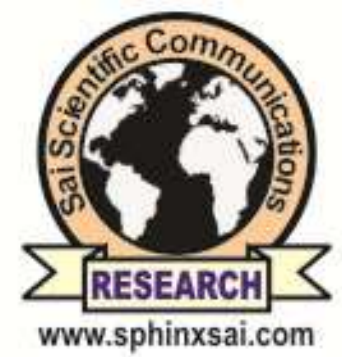

\author{
Ghemtech \\ International Journal of ChemTech Research \\ CODEN (USA): IJCRGG, ISSN: 0974-4290, ISSN(Online):2455-9555 \\ Vol.11 No.05, pp 161-169, \\ 2018
}

\title{
Use of Residual Biomass of African Palm (Elaeis guineensis) in the Removal of Emulsioned Oil in Aqueous Solution
}

\author{
Ángel Villabona Ortiz ${ }^{1}$, Johanna Castellar Cohen ${ }^{2}$, Yessica Cuadro Meza ${ }^{3}$, \\ Candelaria Tejada Tovar ${ }^{4}$, Diofanor Acevedo ${ }^{5 *}$
}
${ }^{1,2,3,4}$ Faculty of Engineering, Chemical Engineering program, Research Group IDAB, University of Cartagena Av. El Consulado, St. 30 No. 48-152. Colombia.

${ }^{5}$ Faculty of Engineering, Research Group Innovation, Agricultural and Agro-industrial Development, University of Cartagena Av. El Consulado, St. 30 No. 48-152. Colombia.

\begin{abstract}
The efficiency of the residual fibre of the African Palm (Elaeis guineensis) was evaluated as an adsorber of emulsified oils against a wastewater treatment process from an oil extraction plant. The initial characterization of the emulsified waters and residual fiber was carried out initially, then the amount of oil removed was evaluated through an experimental design that involved four variables at two levels, whose response variable was the final concentration of the liquid phase in the equilibrium. The removal capacity of the material used was determined from the adsorption isotherms, the Freundlich model being the one that best fits the system. After the experimental procedure, it was concluded that the residual fibre from oil extraction presents a removal rate of $85 \%$ when maintaining the temperature at $25^{\circ} \mathrm{C}$, a pH of 8.5 , agitation of $80 \mathrm{rpm}$ and use an $\mathrm{A} / \mathrm{E}$ ratio of $1: 80$ with particles of $2 \mathrm{~mm}$ at low concentrations, with a maximum adsorption capacity of $112 \mathrm{mg} \mathrm{g}^{-1}$.
\end{abstract}

Keywords : Emulsified waters, Residual fiber, Isothermal, Removal, Turbidity.

\section{Introduction}

The dumping of residual effluents with oil produces direct pollution to water bodies and sectors near the discharge area, since it prevents oxygenation and favours gastrointestinal diseases such as cholera and infectious hepatitis due to bathing or ingestion of contaminated foodstuffs. Therefore, alternatives are being sought that can prevent or mitigate the damage caused to water sources by industrial pollutants; however, most focus on the use of fossil resources and by-products of petrochemical origin, which due to their excessive use, increase the number of pollutants[1,2].Different technologies have been implemented for wastewater treatment, some of them are: dissolved air flotation, coalescence, skimmer and emerging technologies, the latter is a group of new alternatives, which are cost efficient when it comes to putting them into operation, among these technologies are aeration, flocculation, filtration, biological degradation and adsorption.

International Journal of ChemTech Research, 2018,11(05): 161-169.

DOI= http://dx.doi.org/10.20902/IJCTR.2018.110517 
The search for the use of organic materials contributes to the remediation of environmental problems such as water pollution, achieving a better disposal and use of solid waste [3]. Keeping very similar characteristics to the adsorbents mentioned above and bearing in mind that their production is abundant and considered as a waste, the residual fibre resulting from the digestion stage in the extraction process of African palm oil is an adsorbate for the treatment of emulsified wastewater.

Different researchers have tested different adsorbents in the cleaning of oily waters; biomaterials being one of the most promising options. Among the vegetable residues recently used for the removal of emulsified oils, sugar cane bagasse was used to determine the mass of hydrocarbon sorbide per gram of sorbent material at different granulometries with the hydrocarbon used. It was also considered the use of copolymers, specifically di-vinyl benzene Moreno, [3] as well as a resin from a styrene and benzene di-vinyl copolymer by removing more than $89 \%$ of the oil present in the emulsion [4].

Ibrahim et al., [5] conducted an investigation into the extraction of emulsified oil from oily wastewater using barley residues chemically modified with hexadecilpyridinium chloride monohydrate (HCM), observing a strong bond of the CCP to the straw surface and that it creates a non-polar layer on the material increasing its adsorption capacity[6].Also studied at the University of Curtin, Australia, oil adsorption with the straw of barley modified with sodium hydroxide $(\mathrm{NaOH})$, achieving a removal of $88.1 \%$, for oil contained in the solution [5].

Deschamps et al., [7]investigated the recovery of oil from an aqueous solution during a flow through a hydrophobic cotton bed, using cellulose acilation and was defined by sorption and coalescence phenomena. In addition, oxymatrine (OMT) has been used in a spherical cellulose absorbent fitted with acacia bark tannins and Kapoc sawdust (Ceiba) to adsorb oils present in aqueous solutions, achieving removal rates of 50 and 57\% respectively $[8,9]$.

Keeping very similar characteristics to the adsorbents mentioned above and bearing in mind that their production is abundant and little used, the residual fibre resulting from the digestion stage in the extraction process of African palm oil is an alternative adsorbent medium for the treatment of emulsified wastewater, which is an innovative and profitable idea, since the wax palm fibril is considered a waste but in the treatment of aqueous effluents containing heavy oils, has a significant value to be used as adsorbent material.

This research focused on evaluating the efficiency of African palm residual fiber (Elaeis guineensis) as an adsorbent medium for oil in aqueous solution, as well as analyzing physico-chemically the emulsified wastewater and palm fiber microstructure, determining its removal capacity, and identifying the mathematical model and isotherm that best fits adsorption in a batch-type process.

\section{Experimental}

\subsection{Preparation of the adsorbent}

The African palm fibre sample was obtained from the palm oil extraction process as a residual material in the Bolivar department (Colombia). It was washed with distilled water and dried at $80^{\circ} \mathrm{C}$ for $24 \mathrm{~h}$, in order to remove dirt and impurities and avoid biochemical transformations; then it was milled by impact and shear, using a rotor mill at a rotation speed of $1700 \mathrm{rpm}$, finally it was sieved by selecting the sizes of 1 and $2 \mathrm{~mm}[10$, 11].

\subsection{Adsorbent characterization}

The samples were subjected to drying; once free of moisture, they were encapsulated in potassium bromide discs and then characterized by means of Fourier Transform Infrared Spectroscopy (FTIR) with a frequency range between $200 \mathrm{~cm}^{-1}$ and $4000 \mathrm{~cm}^{-1}$, in order to know the functional groups that compose it.

\subsection{Adsorption tests}

Initially the crude oil and water emulsion was poured, a dose of $2 \mathrm{~g}$ or $2.5 \mathrm{~g}$ of residual biomass was added for each concentration and a particle size of $1 \mathrm{~mm}$ or $2 \mathrm{~mm}$, with a contact time of $15 \mathrm{~min}$ [12]. At the end of the time, turbidity of the liquid was measured and the fibre removed from the emulsion, allowed to drain into the environment for $5 \mathrm{~min}$ and SOXHLET analysis was carried out with a factor of 24 without replicates to 
verify the effectiveness of the fibre used[13].Concentrations of oil adsorbed by the fibre were obtained, under each proposed condition, these values were divided by the amount of adsorbent used, resulting in the interchangeability in equilibrium.

\subsection{Adsorption isotherms}

Knowing the interchangeability in equilibrium, the isotherm was constructed that related the interchangeability with the equilibrium concentration of the liquid phase in time, based on Langmuir and Freundlich adsorption models, to determine the behavior of the process in the material used.

\section{Results and discussions}

\subsection{Characterization of wastewater with African palm oil (Elaeis guineensis)}

The characterization of the wastewater generated during the oil extraction process of the African palm is shown in Table 1 . $\mathrm{PH}, \mathrm{COD}, \mathrm{BOD}_{5}$, suspended solids, etc. were analyzed in order to know the conditions under which the wastewater samples must be kept in order to guarantee a low oil concentration.

Table 1: Characterization of wastewater

\begin{tabular}{|l|l|l|}
\hline Sample/ units & Emulsified waters 3rd lagoon. & Emulsified waters 5th lagoon \\
\hline $\mathrm{pH}$ & 8.17 & 8.92 \\
\hline Nitrites $\left(\mathrm{mg} \mathrm{L}^{-1}\right)$ & $<0.025$ & $<0.025$ \\
\hline Turbidity $(\mathrm{UNT})$. & 590.30 & 355.10 \\
\hline Conductivity. $\left(\mathrm{uScm}{ }^{-1}\right)$ & 11990.00 & 10450.00 \\
\hline Oils and fats $\left(\mathrm{mg} \mathrm{L}^{-1}\right)$ & 1.46 & 1.38 \\
\hline Suspended Solids $\left(\mathrm{mg} \mathrm{L}^{-1}\right)$ & 344.00 & 220.00 \\
\hline C.O.D. $\left(\mathrm{mg} \mathrm{L}^{-1}\right)$ & 2854.60 & 1377.20 \\
\hline B.O.D $\left.5 \mathrm{mg} \mathrm{L}^{-1}\right)$ & 1800.00 & 800.00 \\
\hline
\end{tabular}

From Table 1 it can be said that in the lagoons the turbidity is high, evidenced by the large amount of impurities in these, it is also observed that they are basic solutions as evidenced by the $\mathrm{pH}$ of 8,17 and 8.92 respectively for lagoons 1 and 2 . The oil content compared to the permitted levels is high, therefore treatment is necessary before deposition, and based on the amount of solids in suspension is concluded to be highly contaminated.

\subsection{Characterization of African palm fibre}

The residual African palm fibre had a pleasant, brownish smell with a moisture content of $39.5 \%$. The FTIR analysis of residual African palm fibre is shown in Figure 1.

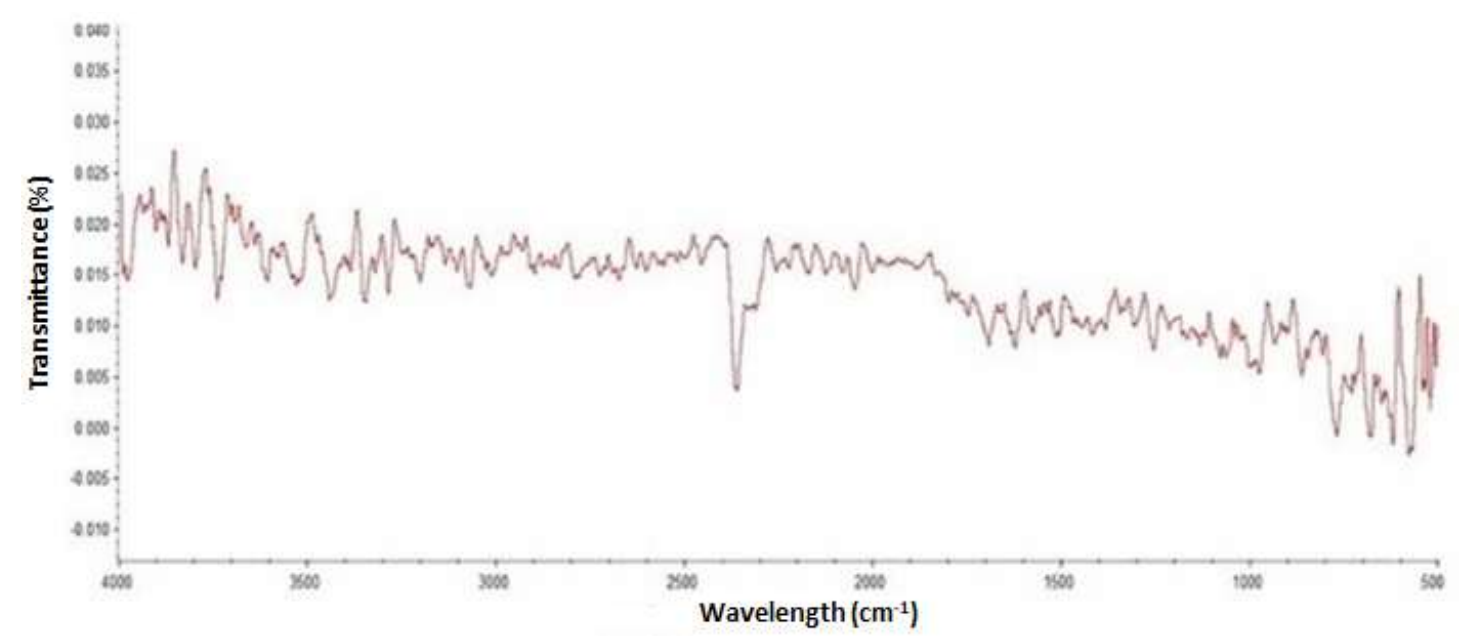


Figure 1 shows the most representative groups of the material, these are characterized by being hydrophobic and oleophilic, i. e. they repel water and have great affinity with oils and fats, respectively. The three peaks that stand out in the FTIR correspond to the $\mathrm{O}-\mathrm{H}$ vibrations, due to the stretching of alcohols, carboxylic and carbonylic acids, whose main adsorbent characteristic is hydrophobic, confirming the feasibility of this material when adsorbing oils in wastewater [14].

\subsection{Kinetics and optimal timing}

Calibration curve, showing fiber kinetics initially at a low oil concentration of $195.8 \mathrm{mg} / \mathrm{L}, \mathrm{pH} 5.9$, turbidity 2842 , particle diameter $2 \mathrm{~mm}, 350 \mathrm{~mL}$ volume without agitation, temperature $=25^{\circ} \mathrm{C}$ (Test A, Figure 2).

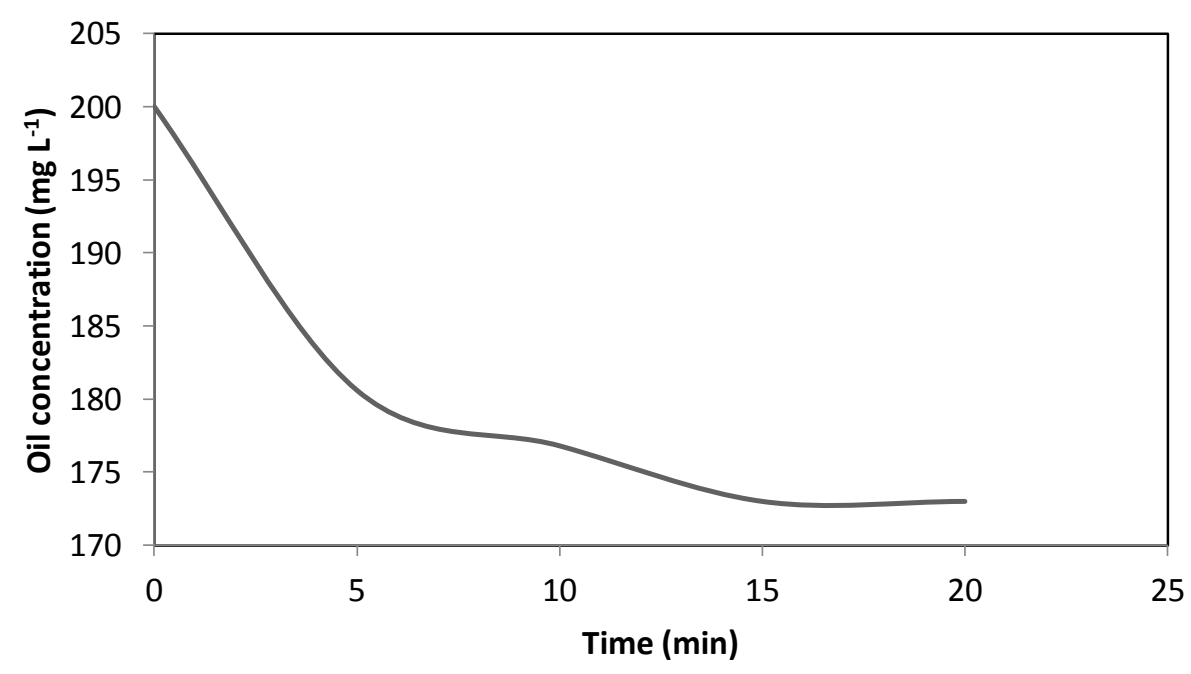

\section{Figure 2.African Palm Fiber Kinetics, Test A}

In Figure 2 it can be seen that during the first 15 min of contact the concentration of oil in the container decreased considerably, and then remain constant when dealing with low concentrations. Figure 3 shows the calibration curve of the fibre kinetics at a high oil concentration of $1692 \mathrm{mg} \mathrm{L}^{-1}, \mathrm{pH}=4.10$, turbidity $=5245$, particle diameter of $2 \mathrm{~mm}, 350 \mathrm{~mL}$ volume without agitation and temperature of $25^{\circ} \mathrm{C}$.

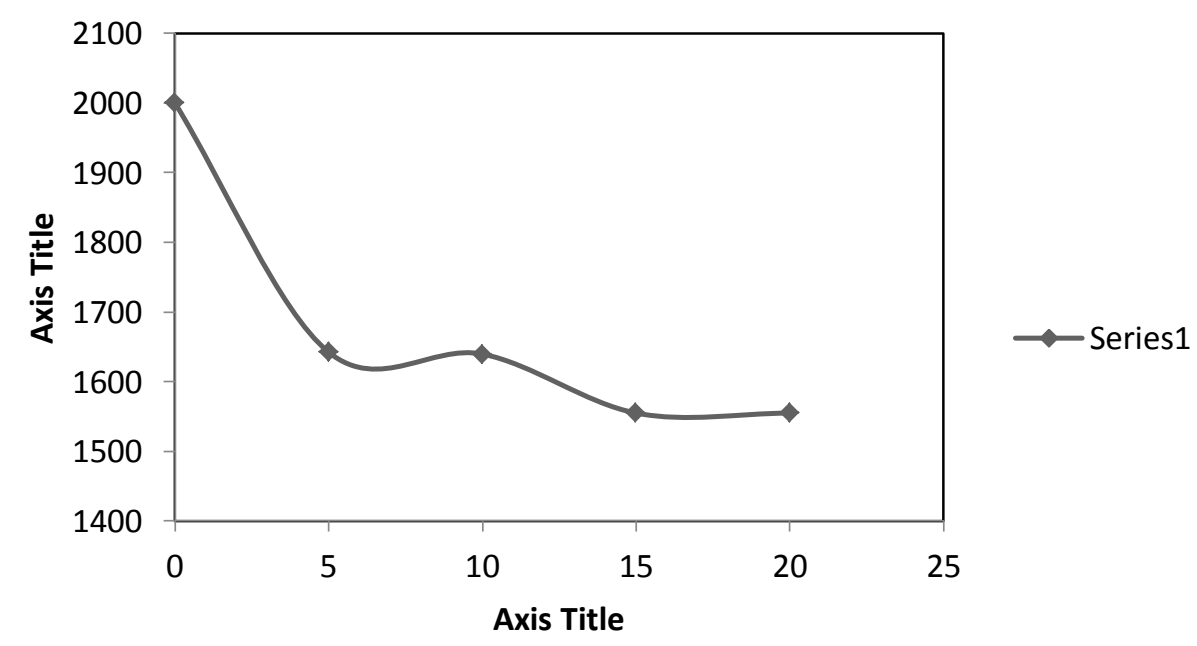

\section{Figure 3.African Palm Fiber Kinetics, Test B}

In Test B (Figure 3) it is observed that the behavior in time is similar to Test A, showing that after 15 min and a significant decrease in concentration, it becomes constant. 


\subsection{Soxhlet Analysis}

At the end of the adsorption tests, a Soxhlet analysis was performed on African palm fibre, obtaining an adsorbed oil concentration of 73 and $113.6 \mathrm{mg} \mathrm{L}^{-1}$ and exchange rates of 37,283 and 6,714 for tests A and B, respectively. The Soxhlet test confirms the low oil removal by residual fiber for high concentrations due to material saturation with oil which obstructs the adsorption process; however for low concentrations it can be said that the removal obtained from Soxhlet is higher compared to calculations made from the calibration curve, because this curve was made from turbidity data, where adding fiber at low solution concentrations affected the reading of the turbidimeter. The kinetic experiments conclude with an optimal contact time of 15 min, since the concentration is maintained constant from this time onwards.

\subsection{Statistical Processing}

The experiments were carried out in duplicate, presenting the mean results with their standard deviation by the StatGraphics program. Figure 4 shows in decreasing order the importance of the effects taken into account in the experimental design. It is evident that the most important are the unitary effects, except for the B effect (amount of fibre), it is important to highlight the impact that the CD and AC correlations have, (sizeagitation) and (concentration-size) respectively, since both relationships are synergistic, i. e. by joining two or more variables that positively affect the experiments, the result is more favorable.

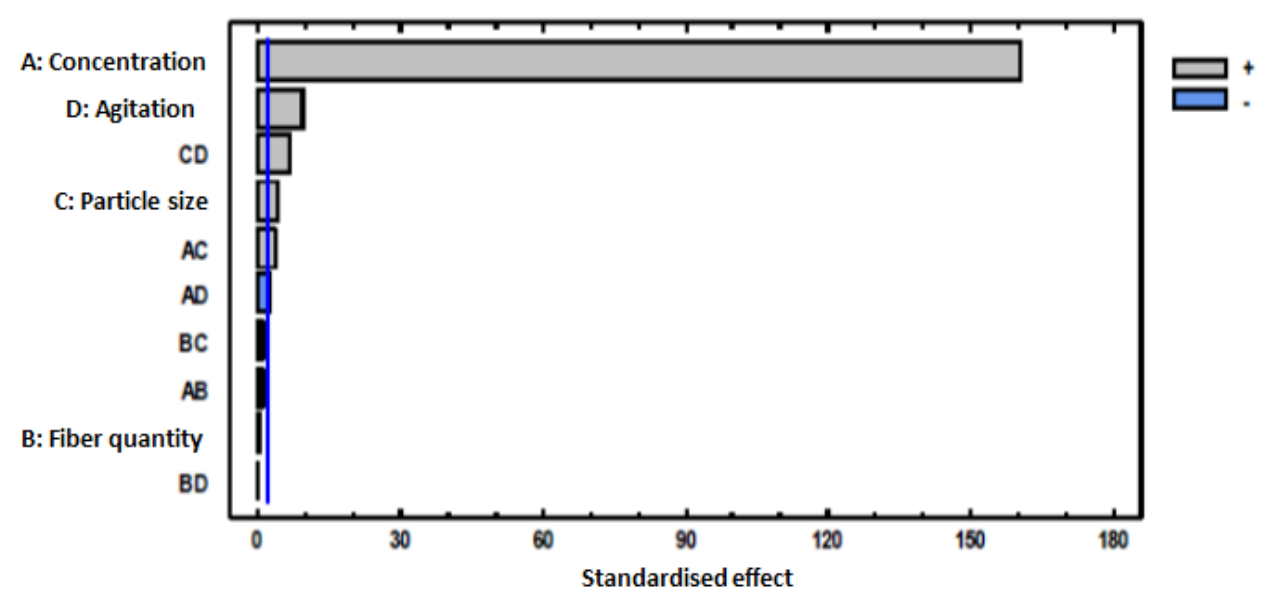

Figure 4.Pareto diagram

Figure 4 suggests that the effect of residual fibre granulometry, in static or dynamic conditions, on adsorption capacity is significant, however the combination of agitation and particle size is a key factor for adsorption capacity.

\subsection{Adsorption isotherms}

Based on the results obtained during the experimental phase, two models of adsorption isotherms were evaluated that allowed to know the behavior of the residual fiber from the extraction process of the African palm, as an oil adsorber in emulsified wastewater, under the conditions in which the highest percentage of removal was observed. Initially, a new experimental stage was carried out in which the adsorption of oil by residual fibre was observed using only $2.5 \mathrm{~g}$ of oil with a diameter of $2 \mathrm{~mm}$ for 12 hours, an agitation of $80 \mathrm{rpm}$; with oil concentration greater than $200 \mathrm{mg} / \mathrm{L}$, to clearly evidence the adsorption isotherms.

Table 2 shows the decrease of the equilibrium concentration in the liquid phase with respect to time, for an initial concentration of $1463 \mathrm{mg} \mathrm{L}^{-1}$. 
Table 2.Balance concentration in the liquid phase.

\begin{tabular}{|l|l|}
\hline $\mathbf{t}(\mathbf{h})$ & $\mathbf{C q}(\mathbf{m g} / \mathbf{L})$ \\
\hline 0.25 & 1293 \\
\hline 0.5 & 1292 \\
\hline 1 & 1291 \\
\hline 2 & 1188 \\
\hline 4 & 1073 \\
\hline 6 & 793 \\
\hline 8 & 63 \\
\hline 10 & 63 \\
\hline 12 & 63 \\
\hline
\end{tabular}

\subsection{Residual fiber oil retention capacity}

Table 3 shows the oil retention in the adsorbent material; it is observed that the higher oil concentration in the filtered solution increases the retention capacity of the material.

Table 3.Oiladsorptionpercentages

\begin{tabular}{|l|l|l|l|l|l|l|l|l|l|}
\hline $\mathbf{C q}(\mathbf{m g} / \mathbf{L})$ & 13,5 & 13,6 & 14 & 22 & 31,2 & 53,6 & 112 & 112 & 112 \\
\hline $\mathbf{t}(\mathbf{h})$ & 0,25 & 0,5 & 1 & 2 & 4 & 6 & 8 & 10 & 12 \\
\hline
\end{tabular}

La Figura 5 muestra la dispersión de los datos y el comportamiento de la capacidad de retención versus la concentración en el equilibrio de la fase liquida.

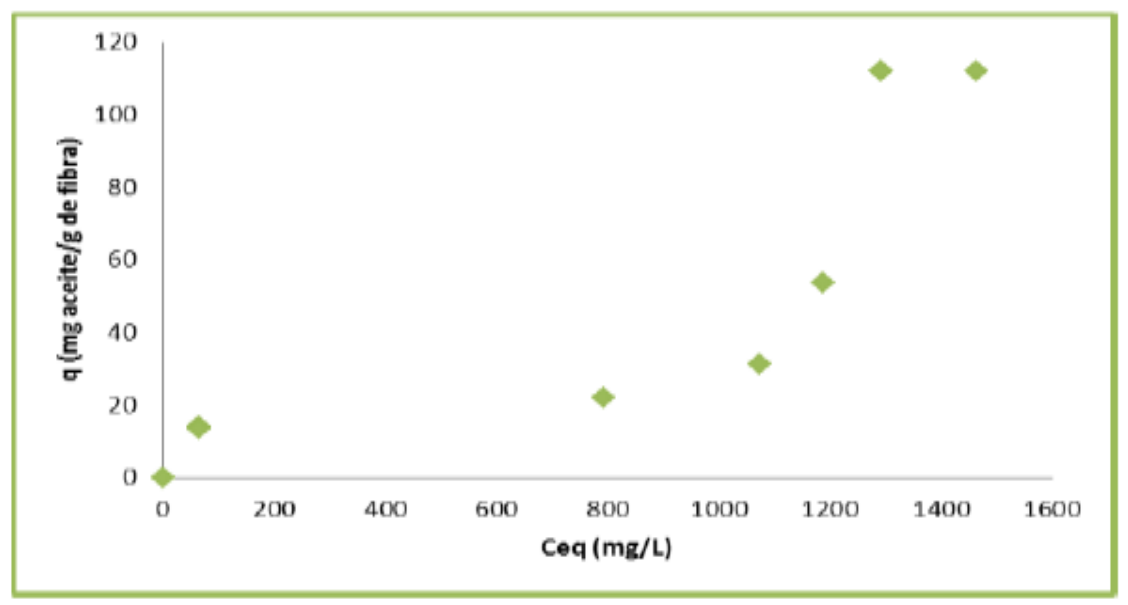

Figure 5.Adsorption isotherms, graph of experimental data

Figure 5 shows that the curve resulting from the dispersion of experimental data has a behavior similar to the isothermal type IV, which is characteristic of mesoporous solids and consists of an increase in the adsorbed quantity, by means of a multilayer filling mechanism.

The experimental results of adsorption in residual fibre were used to determine the equilibrium parameters of both isotherms. For this purpose, it was decided to use widely used adsorption models such as Langmuir and Freundlich. The models allow us to know the maximum quantity that can be fixed on the adsorbent for a given concentration in dissolution; that is, the modelling consists of looking for a theoretical relationship between these two values: Ce (Concentration of the liquid phase in the equilibrium) and qe (Capacity of exchange in the equilibrium). 


\subsection{Adjustment of the Adsorption models.}

The parameters $\mathrm{K}_{\mathrm{L}}$ (Constant equilibrium) and $\mathrm{q}_{\max }$ (Maximum number of molecules that can be adsorbed) of the Langmuir isotherms, $\mathrm{K}_{\mathrm{f}}$ and $\mathrm{n}$ of the Freundlich isotherms and the regression coefficients were obtained through graph $\frac{1}{C_{e q}}$ vs. $\frac{1}{q}$ and $\log C_{e q}$ vs. $\log$ q vs. q, respectively.

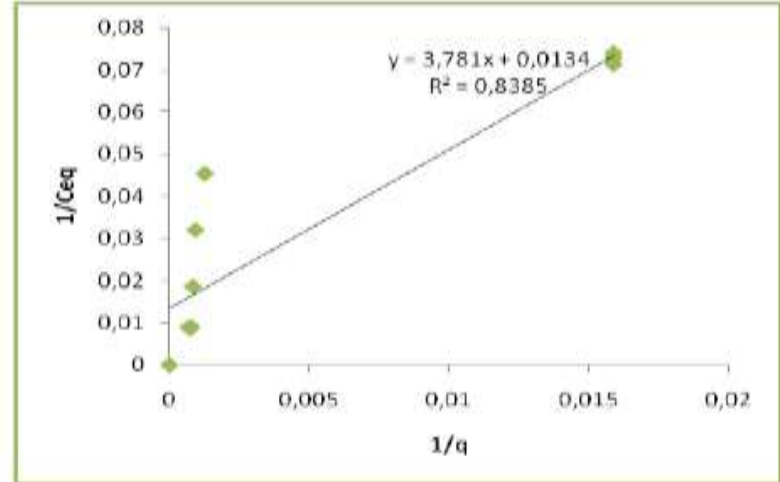

(a)

\section{Figure}

\section{FreundlichT}

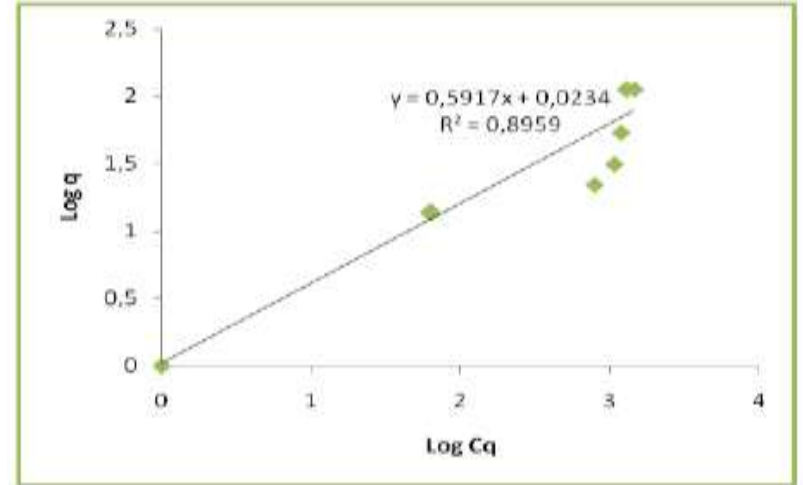

(b)

When talking about the Langmuir model, it is said that the favorability of adsorption depends on parameter $\mathrm{K}_{\mathrm{L}}$. The previous table shows that the parameter has a value lower than the unit, which indicates that adsorption in these experiments is favorable [15].

Table 4.Parameters of adsorption models

\begin{tabular}{|l|l|l|}
\hline $\mathrm{z}$ & Langmuir & Freundlich \\
\hline $\mathrm{K}_{\mathrm{L}}$ & 0,0023 & ----- \\
\hline $\mathrm{q}_{\max }$ & 20 & ----- \\
\hline $\mathrm{R}^{2}$ & 0,839 & 0,896 \\
\hline $\mathrm{K}_{\mathrm{f}}$ & ----- & 1,615 \\
\hline $\mathrm{n}$ & ------ & 0,592 \\
\hline
\end{tabular}

3.9 The isotherms of Langmuir and Freundlich are plotted below:

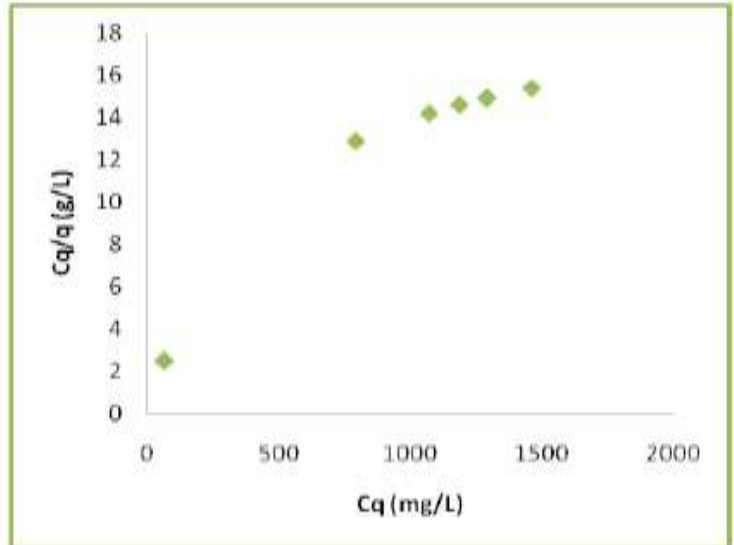

(a)

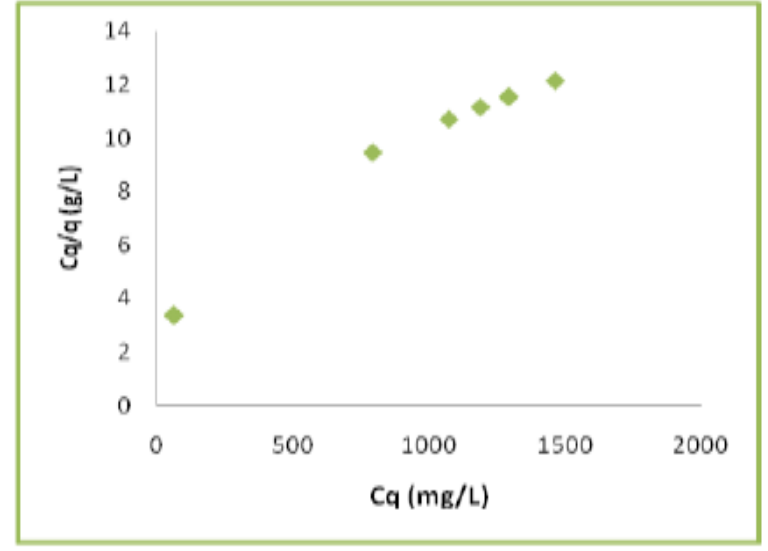

(b)

Figure 7.Adsorption isotherms: (a) Langmuir model. (b) Freundlich Model

Figure 7a is similar to class $\mathrm{L}$ isotherms containing Langmuir type curves. In these, there is no strong competition from the solvent to occupy sites on the adsorbent surface or the adsorbate contains linear molecules in its coordination sphere which leads to greater axial adsorption parallel to the surface. When performing the 
data dispersion with the Langmuir model, a setting of 0.9616 was obtained; and $q=20$ indicated that the adsorption capacity is good, however the $\mathrm{K}_{\mathrm{L}}$ value is 0.0023 , i. e. the adsorbate/adsorbent affinity is low. In the Freundlich model, the favorability of adsorption is measured with parameter $\mathrm{n}$, it is said that adsorption is favorable if and only if $n$ is smaller than the unit. Table 4 shows that the parameter has a value lower than the unit, which indicates that adsorption is favorable, according to this model. The $\mathrm{K}_{\mathrm{F}}$ values are directly related to the adsorption capacity of the material used, i. e. it indicates that the adsorbent has a high adsorption capacity [16].

The dispersion of the data in Figure $7 \mathrm{~b}$, showed an adjustment of 0.9865 , reaffirming the class $\mathrm{L}$ of the isotherm and with the values obtained from $n$ and $\mathrm{K}_{\mathrm{f}}$, the favorability in the adsorption process and the high adsorption of the material used was demonstrated. Analyzing the regression coefficients, it is observed that the curves have a good fit in both models; however, considering the predominant form of the obtained isotherms, $\mathrm{i}$. e. multi-layer filling and the greater adjustment coefficient, it can be affirmed that the oil adsorption in emulsified waters with African palm residual fibre, is subject to the Freundlich model.

\section{Conclusions}

When the physical and chemical characterization of the material was carried out by FTIR, it was observed that it has a hydrophobic chemical composition, reflected in the intensities and proximity to the bands. The two methods applied to calculate the response variable make clear the non-applicability of the turbidity reading method, since it prevents data analysis when agitation is applied. It was determined that the residual fibre used can adsorb up to $85 \%$ of the emulsified oil in wastewater, using a particle size of $2 \mathrm{~mm}$, shaking at 80 $\mathrm{rpm}$ and adding a high amount of material. Bearing in mind the adsorption isotherms, it can be said that the process is carried out by multi-layer filling, because the adsorption process became constant after $15 \mathrm{~min}$, then from $2 \mathrm{~h}$ started adsorbing again until at $6 \mathrm{~h}$ again presented a constant behavior, according to this the adsorbent material is porous, porous meso-type. The best fitting model was found to be the Freundlich (multi-layer) model, with which it was found that the highest oil retention capacity in the material was $112 \mathrm{mg} \mathrm{g}^{-1}$.

\section{References}

1. Esquivel, M. "Síntesis, caracterización y aplicaciones de materiales periódicos meso porosos órgano silícico", Tesis doctoral, Universidad de córdoba, Facultad de Ciencias: Córdoba, 2011.

2. Benito, J. "Informe de estado de los ambientes marinos y costeros en Colombia. Instituto de Investigaciones Marítimas y Costeras: Santa Marta, Colombia", 2004.

3. Moreno, J. Moral, R., Morales-García, J.L., Pascual, J.A., Bernal, M.P. "De residuo a recurso: el camino hacia la sostenibilidad. Ediciones Mundi-Prensa", Red española de compostaje. Madrid, España, 2015.

4. Sánchez, N., Vazquez, M., Torresi, R. "Degradación y adsorción del colorante AZO RR239 en solución acuosa, por partículas de hierro "zero-valente" a nano escala, inmovilizadas sobre aserrín", Instituto de Química; Facultad de Ciencias Exactas y Naturales; Universidad de Antioquia: Medellín, Colombia, 2010.

5. Iibrahim, S., Ha-M, A., Wang S. "Removal of emulsified food and mineral oils from wastewater using surfactant modified barley straw",Bioresource Technology, vol 100, pp. 5744-5749, 2009.

6. Sharif, I., Shaobin, W., Ang, H. "Removal of emulsified oil from oily wastewater using agricultural waste barley straw. University of Technology, GPO Box U1987, Perth, WA 6845: Australia, 2009.

7. Deschamps, G., Caruel, H., Borredon, M., Albasi, C., Riba, J., Bonnin, C., Vignoles, C. "Oil Removal from Water by Sorption on Hydrophobic Cotton Fibers. 2. Study of Sorption Properties in Dynamic Mode", Laboratories de Chimie Agro-Industrially, UMR INRA/INP: France, 2003.

8. Yan, S., Chung-Xiang, L., Ming-Hua, L. "Equilibrium Adsorption Behaviors and Kinetic Characteristics of Oximatrine on a Spherical Cellulose Adsorbent.Environment and Resources, Fuzhou University, China, 2011.

9. Teik-Thye L., Huang X. "In situ oil/water separation using hydrophobic-oleophilic fibrous wall: A labscale feasibility study for groundwater cleanup”,Journal of Hazardous Materials, vol. 137, pp..820-826, 2006.

10. Guevara, J., Mendoza, E. "Adsorción de cadmio y plomo mediante biomasa algal no viva, Tesis de grado", Universidad de Cartagena, departamento de postgrado: Cartagena de Indias, 2002. 
11. Contreras, G., Rodríguez, R. "Caracterización y adecuación de residuos sólidos húmedos generados en maltearía tropical, Tesis de grado. Universidad de Cartagena, facultad de química y farmacia: Cartagena de Indias, 1993.

12. Romero, J., Parra, F., Cano, I., Fuentes, R. "Biosorción De Cu(Ii) Por Biomasa De Agave Tequilana Weber (Agave Azul)", Universidad de Guanajuato, Departamento de Ingeniería Química, Noria Alta S/N, Guanajuato, México, 2011.

13. Nuñez, C. "Extracciones con equipo soxhlet, Texto libre y gratis para usos no lucrativos nombrando la fuente. Visto online: Extracciones con equipo soxhlet", Texto libre y gratis para usos no lucrativos nombrando la fuente, 2010.

14. Pinzón, M., Cardona, A. "Caracterización de la cáscara de naranja para su uso como material bioadsorbente, Grupo de Investigación en Tecnologías Verdes (GTV). Instituto de Investigación en producción Verde (IPV), Universidad de Pamplona, Sede Villadel Rosario, Norte de Santander,Colombia, 2008.

15. Martínez, J. "Materiales zeolíticos: síntesis, propiedades y aplicaciones, Adsorción e intercambio iónico en zeolitas", consultado en: https://publicaciones.ua.es/va/detall.php?idet=621, 2003.

16. Akmil, C. "Applicability of the various adsorption models of three dyes adsorption onto activated carbon prepared waste apricot”,Journal of Hazardous Materials, vol. B135, pp. 232-241, 2006. 